University of Nebraska - Lincoln

DigitalCommons@University of Nebraska - Lincoln

2012

\title{
Quantitative 3-D Elemental Mapping by LA-ICP-MS of a Basaltic Clast from the Hanford 300 Area, Washington, USA
}

\author{
Sheng Peng \\ University of Texas at Arlington \\ Qinhong Hu \\ University of Texas at Arlington, maxhu@uta.edu \\ Robert Ewing \\ lowa State University \\ Chongxuan Liu \\ Pacific Northwest National Laboratory, chongxuan.liu@pnl.gov \\ John M. Zachara \\ Pacific Northwest National Laboratory, john.zachara@pnl.gov
}

Follow this and additional works at: https://digitalcommons.unl.edu/usdoepub

Part of the Bioresource and Agricultural Engineering Commons

Peng, Sheng; Hu, Qinhong; Ewing, Robert; Liu, Chongxuan; and Zachara, John M., "Quantitative 3-D Elemental Mapping by LA-ICP-MS of a Basaltic Clast from the Hanford 300 Area, Washington, USA" (2012). US Department of Energy Publications. 243.

https://digitalcommons.unl.edu/usdoepub/243

This Article is brought to you for free and open access by the U.S. Department of Energy at DigitalCommons@University of Nebraska - Lincoln. It has been accepted for inclusion in US Department of Energy Publications by an authorized administrator of DigitalCommons@University of Nebraska - Lincoln. 


\title{
Quantitative 3-D Elemental Mapping by LA-ICP-MS of a Basaltic Clast from the Hanford 300 Area, Washington, USA
}

\author{
Sheng Peng, ${ }^{\dagger}$ Qinhong Hu, ${ }^{* \dagger}{ }^{\dagger}$ Robert P. Ewing, ${ }^{\ddagger}$ Chongxuan Liu, ${ }^{\S}$ and John M. Zachara ${ }^{\S}$ \\ ${ }^{\dagger}$ Department of Earth and Environmental Sciences, University of Texas at Arlington, Arlington, Texas 76019, United States \\ ${ }^{\ddagger}$ Department of Agronomy, Iowa State University, Ames, Iowa 50011, United States \\ ${ }^{\S}$ Pacific Northwest National Laboratory, Richland, Washington 99354, United States
}

Supporting Information

\begin{abstract}
Laser ablation with inductively coupled plasmamass spectrometry (LA-ICP-MS) was used to measure elemental concentrations at the $100-\mu \mathrm{m}$ scale in a 3 -dimensional manner within a basaltic clast sample collected from the Hanford 300 Area in south-central Washington State, United States. A calibration method was developed to quantify the LAICP-MS signal response using a constant-sum mass fraction of eight major elements; the method produced reasonable concentration measurements for both major and trace elements when compared to a standard basalt sample with known concentrations. 3-Dimensional maps (stacked 2-D contour layers, each representing $2100 \mu \mathrm{m} \times 2100 \mu \mathrm{m})$ show relatively uniform concentration with depth for intrinsic elements such as $\mathrm{Si}, \mathrm{Na}$, and $\mathrm{Sr}$. However, $\mathrm{U}$ and $\mathrm{Cu}$ accumulation were observed near the sample surface, consistent with the site's release history of these contaminants. $\mathrm{U}$ and $\mathrm{Cu}$ show substantial heterogeneity in their concentration distributions within horizontal slices, while the intrinsic elements are essentially uniformly distributed. From these measured $U$ concentrations and published grain size distributions, gravel and cobbles were estimated to contain about $1 \%$ of the contaminant $\mathrm{U}$, implicating the coarse fraction as a long-term release source.
\end{abstract}

\section{INTRODUCTION}

Contaminant release from Department of Energy sites threatens groundwater and riparian quality in many locations, most notably at the Hanford, Savannah River, Oak Ridge, and Nevada Test sites. At the Hanford site, an estimated 202,703 kg of $U$ was released to the vadose zone during site operations between 1940 and 1990, with three major contaminant plumes identified. ${ }^{1}$ These Hanford $U$ plumes have a combined area of $1.6 \mathrm{~km}^{2}$, within which dissolved $\mathrm{U}$ concentrations exceed the U.S. Environmental Protection Agency's maximum contamination level of $30 \mu \mathrm{g} / \mathrm{L}\left(1.2 \times 10^{-7} \mathrm{~mol} / \mathrm{L}\right)$.

One of the plumes, located at the Hanford 300 Area, contains an estimated $33-59 \mathrm{Mg}$ of uranium (U), $240 \mathrm{Mg}$ of copper $(\mathrm{Cu})$, and $113 \mathrm{Mg}$ of aluminum $(\mathrm{Al})$, along with other dissolved metals from the fuel fabrication process. These materials were deposited in process ponds and trenches over a period of approximately 32 years, from 1943 to $1975 . .^{2,3}$ Uranium in the contaminated sediments at the 300 Area was found in several forms, including low-solubility uranyl-copperphosphate (metatorbernite) and cuprosklodowskite, highsolubility uranyl carbonate and uranophane, and surfacecomplexed uranyl species. Long-term release of $U$ is likely controlled by those forms of uranium that are entrapped in C-, $\mathrm{Al}$-, and Si-rich coatings, intragranular pore domains, and fracture spaces. 2,4
Sediments in the Hanford 300 Area are up to 92 wt \% gravel and cobbles $(>2 \mathrm{~mm}){ }^{2}$ The fines (silt and clay $<53 \mu \mathrm{m}$ ) comprise as little as $2 \%$ of the total sediment mass, but hold a disproportionately high concentration of U. ${ }^{5}$ Concentrations and speciation of $U$ in the fines have been investigated using a variety of methods. ${ }^{4,6,7} \mathrm{U}(\mathrm{VI})$ speciation has been primarily determined by X-ray absorption spectroscopy $\left(\mathrm{XAS}^{2,8}\right)$, and by cryogenic laser-induced fluorescence spectroscopy ( CLIFS $^{7}$ ). Both XAS and CLIFS measurements indicate that contaminant $\mathrm{U}(\mathrm{VI})$ exists primarily in the form of carbonate and phosphate precipitates in the upper vadose zone, and as adsorption complexes on phyllosilicates and Fe(III) oxides in the lower vadose zone. ${ }^{1}$ Whereas groundwater $U$ concentrations range from 5 to $150 \mu \mathrm{g} / \mathrm{L}$, solid-phase $\mathrm{U}$ concentrations in sediment fines can be as high as $250 \mathrm{mg} / \mathrm{L} .{ }^{4}$ However, few studies have examined the concentration of $U$ in gravel and cobbles, because of the low concentration and detection limit with the abovementioned methods. For example, the operational detection limit for U(VI) via XAS is approximately $50 \mathrm{mg} / \mathrm{kg}$, and that for CLIFS is $15 \mathrm{mg} / \mathrm{kg}$; these limits exceed the background $U$

Received: July 15, 2011

Revised: December 2, 2011

Accepted: January 27, 2012

Published: January 27, 2012 
concentration in Hanford sediments, which ranges from 1.47 to $5.10 \mathrm{mg} / \mathrm{kg} .{ }^{1}$ Furthermore, what is usually measured for gravel and cobbles is the total concentration, rather than a distribution of spatial concentrations (e.g., refs 5,9).

Kinetically controlled release of U(VI) has been observed for both uranyl and nonuranyl mineral structures and surface complexes (e.g., refs 5,10,11). Such release may function as a long-term contaminant resupply mechanism even after active remedial activities, resulting in persistent groundwater contamination. The kinetic mass transfer is conditioned on several multiscale processes, including dissolution/desorption, intragrain diffusion, chemical kinetics, and flow conditions. ${ }^{5,10-12}$ However, most research on kinetic release behavior is based on modeling interpretation of laboratory column tracer experiments, few of which worked with gravel or cobbles (e.g., 5). To our knowledge, there are no experimental studies investigating $\mathrm{U}$ concentration profiles (i.e., from surface to deep inside) within the coarser particles. Such a study would better constrain the contaminant distribution across particle sizes, inform remediation efforts, and aid understanding of long-term kinetic release from the coarse sediments.

Laser ablation, coupled with inductively coupled plasma-mass spectrometry (LA-ICP-MS), is a method for multielemental, microscale concentration measurements, with a higher sensitivity than can be achieved with XAS or CLIFS. Many geological, environmental, and forensic applications of LA-ICPMS have been reported (e.g., refs 13-15). However, some have considered LA-ICP-MS only semiquantitative, because of the lack of matrix-matching calibration standards. ${ }^{16}$ Attempts to more rigorously quantify LA-ICP-MS data involve calibration of the (changing) mass response of the ICP-MS, and correction for the difference in ablation yield between the sample and calibration standard. ${ }^{15}$ Two calibration methods are commonly used, the most common of which requires an internal standard. ${ }^{17}$ The internal-standard method requires that the concentration of at least one (usually major) element be known for, and uniformly distributed within, the sample. However, this is rarely the case in geological samples, and in fact, smaller laser spots are expected to yield greater local geochemical heterogeneity. The other method utilizes the sum of $100 \%$ of all sample constituents as a normalization standard, and therefore does not require an internal standard; ${ }^{18-22}$ this method is better suited to heterogeneous geological samples. $^{22,24}$

In this paper we present a methodology for automated 3-D LA-ICP-MS elemental mapping and develop a modified calibration algorithm to the aforementioned sum to $100 \%$ method. We apply the methods to a basaltic clast sample from the Hanford 300 Area, and discuss results for both intrinsic and contaminant elements. Finally, we examine implications of our findings for the $U$ mass fraction distribution in coarse Hanford sediments.

\section{MATERIALS AND METHODS}

2.1. Sample Description. Sediment samples $(<8 \mathrm{~mm}$ fraction) were collected from the smear zone (lower vadose zone, $\sim 3-4 \mathrm{~m}$ below ground surface) of the Integrated FieldScale Research Challenge (IFRC) site at the Hanford 300 Area. The site is $\sim 100 \mathrm{~m}$ from the Columbia River, and the smear zone is affected by river stage oscillations with an amplitude of up to $1 \mathrm{~m} / \mathrm{d}$ and $>2 \mathrm{~m}$ per season. ${ }^{23}$ Samples were air-dried and dry-sieved into four size classes of $<75 \mu \mathrm{m}, 75-500 \mu \mathrm{m}, 500-$ $2000 \mu \mathrm{m}$, and $2-8 \mathrm{~mm}$, having respective mass fractions of
$4.4 \%, 20.3 \%, 33.4 \%$, and $41.8 \%$. The $2-8 \mathrm{~mm}$ size-fraction samples were visually classified by mineralogy, with $83 \%$ by weight being basaltic clasts. This classification was confirmed by microscopic observation, which showed compositions of $\sim 70 \%$ pyroxene and $\sim 30 \%$ plagioclase within the basaltic clasts. One typical piece of basaltic clast was selected for LA-ICP-MS analysis.

2.2. LA-ICP-MS Experiments. A UP-213 laser ablation system (New Wave, Freemont, CA), interfaced with a PerkinElmer/SCIEX ELAN DRC II (Sheldon, CT) ICP-MS system, was used to characterize the elemental distribution in the basaltic clast sample. Liquid standards of $2 \mu \mathrm{g} / \mathrm{L}{ }^{6} \mathrm{Li},{ }^{45} \mathrm{Sc}$, ${ }^{115} \mathrm{In}$, and ${ }^{209} \mathrm{Bi}$ were continuously introduced to monitor the ICP-MS stability and provide a basis for time-drift correction; the simultaneous solution nebulization and laser ablation-ICPMS has been used by other researchers. ${ }^{24-26}$ The ICP-MS was tuned to keep the ${ }^{115}$ In signal response high, while maintaining the signal response oxide ratio $\left({ }^{156} \mathrm{CeO} /{ }^{140} \mathrm{Ce}\right)$ and doubly charged $\mathrm{Ba}^{2+} / \mathrm{Ba}^{+}(70 / 140)$ less than $3 \%$, which meets the ICPMS's specification. More details on instrumental and operational conditions of LA-ICP-MS are provided in the Supporting Information.

Laser ablation was conducted in a $2100 \mu \mathrm{m} \times 2100 \mu \mathrm{m}$ area on the surface of the basaltic clast sample. The laser spot was set to $100 \mu \mathrm{m}$ in diameter, so with $100 \mu \mathrm{m}$ spacing between spots, $21 \times 21=441$ spots were sampled for each depth (layer) in the mapped area. An automatic grid spot analysis protocol was developed by synchronizing the timing between laser firing and ICP-MS data collection for each spot. Each layer required 4-7 h to complete depending on the number of laser pulses, with more pulses requiring more time. Each grid spot in the sampling area received nine sets of pulses, numbering (in order) $20,20,60,60,200,200,500,500$, and 500. Depths of some test ablation craters in a polished Hanford basaltic grain were measured with an Alpha-Step IQ Surface Profiler (KLA Tencor, Milpitas, CA), giving a mean ablated depth in this rock of $14 \mu \mathrm{m}$ per 500 pulses from this system.

Standard reference material 610 (SRM 610), obtained from National Institute of Standards and Technology (NIST, Gaithersburg, MD), was chosen as the external reference material for quantitative calibration. SRM 610 has a concentration of $\sim 500 \mathrm{ppm}$ for about sixty trace elements. Before, during, and after the basaltic clast measurements, SRM 610 was ablated and measured at 6 different locations, with each location having spot size of $100 \mu \mathrm{m}$ and receiving 20 laser pulses.

2.3. LA-ICP-MS Data Correction and Calibration. Signal intensity (counts per second, CPS) is proportional to the sample concentration $(C)$ and the ablation yield volume $(V)$ :

$$
\begin{aligned}
& \mathrm{CPS}_{r}^{i}=k_{r}^{i} V_{r} C_{r}^{i} \\
& \mathrm{CPS}_{s}^{i}=k_{s}^{i} V_{s} C_{s}^{i}
\end{aligned}
$$

where $k^{i}$ is a lumped coefficient which accounts for the influence of different ablation properties, variations in the laser output or interaction with the sample, and variations in aerosol transport. The subscripts $r$ and $s$ respectively refer to reference material and sample, while the superscript $i$ denotes the 
element being measured. Therefore, the concentration of element $i$ in the sample can be calculated as

$$
\begin{aligned}
C_{s}^{i} & =\frac{\mathrm{CPS}_{s}^{i}}{k_{s}^{i} V_{s}^{i}}=\operatorname{CPS}_{s}^{i}\left(\frac{C_{r}^{i}}{\operatorname{CPS}_{r}^{i}}\right)\left(\frac{k_{r}^{i} V_{r}}{k_{s}^{i} V_{s}}\right)=K^{i} \operatorname{CPS}_{s}^{i}\left(\frac{C_{r}^{i}}{\operatorname{CPS}_{r}^{i}}\right) \\
K^{i} & =\frac{k_{r}^{i} V_{r}}{k_{s}^{i} V_{s}}
\end{aligned}
$$

where $K^{i}$ is the ratio of ablation yield parameters between reference material and sample. In each laser firing, $V_{r}$ and $V_{s}$ are the same for all elements in reference and sample, respectively. $k^{i}$ can be different for each element, but the ratio $k_{r}^{i} / k_{s}^{i}$ should be constant across all elements, considering the similarity of laser output and aerosol transportation to ICP-MS for each element. Therefore, $K^{i}$ can be assumed to be constant for all elements.

If an internal standard were available to ratio the signal response, then we would have

$$
K^{i s}=\left(\frac{C_{s}^{i s}}{\mathrm{CPS}_{s}^{i s}}\right) /\left(\frac{C_{r}^{i s}}{\mathrm{CPS}_{r}^{i s}}\right)
$$

where the superscript is denotes internal standard, and we could calculate $C_{s}^{i}$ with an internal standard as

$$
C_{s}^{i}=\operatorname{CPS}_{s}^{i}\left(\frac{C_{r}^{i}}{\mathrm{CPS}_{r}^{i}}\right)\left(\frac{C_{s}^{i s}}{\mathrm{CPS}_{s}^{i s}}\right)\left(\frac{\mathrm{CPS}_{r}^{i s}}{C_{r}^{i s}}\right)
$$

However, as discussed in Section 1, there is usually no suitable internal standard, especially for materials with heterogeneous mineralogical and chemical composition. An alternative quantification method, originally proposed by Gratuze, ${ }^{18}$ uses the total concentration of oxides of all elements $\left(C_{s}^{o}\right)$ as the basis for calibration:

$$
\sum_{o=1}^{n} C_{s}^{o}=100 \% \mathrm{wt}
$$

However, different oxide states (e.g., $\mathrm{Fe}$ ) increase the uncertainty in back-calculating $C_{s}^{i}$ from $C_{s}^{0}$, as ICP-MS analyses do not distinguish between oxidation states for $\mathrm{Fe}$. Furthermore, collecting all elements requires an extremely wide dynamic range of the detector, posing a challenge. ${ }^{27}$ Therefore, in this work we modify Gratuze's ${ }^{18}$ method to use as a basis the sum of eight major elements $(\mathrm{Na}, \mathrm{Mg}, \mathrm{Si}, \mathrm{Al}, \mathrm{K}, \mathrm{Ca}$, $\mathrm{Fe}$, and $\mathrm{Mn}$ ). These elements show a stable value of $51.8 \pm$ $1.1 \%$ for the combined elemental composition across 13 different rocks including 2 basaltic clast samples (Table S2). With the unit of concentration being $\mathrm{mg} / \mathrm{kg}$ (ppm), eq 6 can be modified to

$$
\sum_{i=1}^{8} C_{s}^{i}=51.8 \% \times 10^{6}
$$

and combining eqs 2 and $7, K^{i}$ can be calculated as

$$
K^{i}=\frac{51.8 \% \times 10^{6}}{\sum_{i=1}^{8} \mathrm{CPS}_{s}^{i}\left(\frac{C_{r}^{i}}{\mathrm{CPS}_{r}^{i}}\right)}
$$

This modified method is derived explicitly based on the concentration of each element without distinguishing between oxidation states, and requires measurement of only 8 major elements by LA-ICP-MS; it is therefore more practical to implement than Gratuze's original method. ${ }^{18}$ Of course, if elemental composition data were available for a specific geologic sample, the constant mass fraction could be modified accordingly.

Before using the equations above to calculate $C_{s}^{i}$, all $\mathrm{CPS}^{i}$ data were normalized to a per-pulse basis, because different numbers of pulses were applied to the reference material, and to different depths in the basaltic clast sample. CPS ${ }^{i}$ per-pulse data were then corrected for time drift of the ICP-MS according to the liquid internal standards' response. Signal intensities for the four liquid internal standards were essentially stable over 3 days' run time, with a slight decrease over the first $28 \mathrm{~h}$ (see Figure $\mathrm{S} 1$ for details). The $\mathrm{CPS}^{i}$ for each liquid internal standard was normalized based on the signal intensity at the first data point of LA-ICP-MS mapping for the basaltic clast sample. Normalized signal intensities, with values $0.6-1.2$, were then used as the time drift correction factor (TD) to account for temporal signal intensity changes of ICP-MS:

$$
\text { Corrected } \mathrm{CPS}^{i} \text { per pulse }=\mathrm{CPS}^{i} \text { per pulse } / \mathrm{TD}
$$

The TD values for ${ }^{6} \mathrm{Li},{ }^{45} \mathrm{Sc},{ }^{115} \mathrm{In}$, and ${ }^{209} \mathrm{Bi}$ were used for elements within atomic mass ranges of $<23,23-63,85-142$, and 208-238, respectively.

2.4. Mapping Display Routine. Elemental concentrations at the 441 sampling spots were identified by their $x-y$ grid coordinates, so concentrations could be displayed by location; a similar mapping routine was described in Koenig et al. ${ }^{27}$ Gridbased concentration data were compiled for each element and depth in an Excel spreadsheet, then imported into the Surfer plotting program (Golden Software, Golden, CO). Surfer's kriging algorithm was used to interpolate the map surface between grid points. The resulting 2-D contour plots of different depths were skewed and overlapped with fixed interval in Adobe Photoshop (Adobe, San Jose, CA) to manually generate a stack of 2-D maps (i.e., a 3-D map) for each element. Each element was assigned a consistent false-color spectrum to span the concentration range found across all layers, with colors ranging from green and yellow for low and moderate concentrations to dark red for high concentrations.

\section{RESULTS AND DISCUSSION}

3.1. Data Processing and Quality Assessment. The value of $K^{i}$ was calculated based on the time-drift corrected signal intensity per pulse for each grid location and depth. Calculated $K^{i}$ values at each depth are usually in the range of $0.5-5$, and high $K^{i}$ values occur only in a few specific areas (Figure S2). A high value of $K^{i}$ corresponds to a low signal intensity (eq 3 ), and hence is likely to be caused by small $V_{s}$. For example, the highest $K^{i}$ in layer 2 is 116; at this spot the $\mathrm{CPS}^{i}$ for $\mathrm{U}$ is 10.6, while the average CPS for $\mathrm{U}$ in this layer is 338. Likewise, the average $\mathrm{CPS}^{i}$ for $\mathrm{U}$ in layer 2 for $K^{i}>5$ is 53.6, while that for $K^{i}<5$ is 367.3. But small values of $V_{s}$ increase the measurement uncertainty. Therefore, all points having $K^{i}>5$ were discarded from subsequent analysis. Because the high $K^{i}$ spots account for fewer than $3 \%$ of the data points, removing them has a negligible effect on the mapping results. The average $K^{i}$ value after removing the $>5$ values is 1.5 , with a standard deviation of 0.6 . This indicates similarity and 
consistency between the reference material and sample with respect to ablation properties and aerosol transport conditions, which in turn justifies the data quality of the experiment. The layer-average $K^{i}$ values from surface to interior were 1.10, 1.40, $1.18,1.27,1.31,1.40,1.85,1.95$, and 1.94. Considering that other ablation properties and transport conditions are likely similar, the slightly increasing $K^{i}$ value probably indicates ablation yield volume $V_{s}$ decreased with increasing depth. This is not unexpected for depth profiling analyses of LA-ICP-MS, since holes tend to become slightly narrower with increasing laser pulses and sampling depth. ${ }^{28}$ Our tests show that laser pulse is linear to crater depth of at least $35 \mu \mathrm{m}$ (the upper limit for the profilometer used). For the sake of convenience our analysis assumes constant per-pulse ablation volume with depth, as the end depth was $58 \mu \mathrm{m}$ in this study.

Averaged $C_{s}^{i}$ for the elements of interest (both overall volume average, and average of the deepest three ablation layers), including the eight major elements, were compared to the concentrations of the USGS Oregon basalt sample (BCR2 ). The cumulative mass fraction of the eight major elements of the Hanford basaltic clast (52.0\% and 51.8\%) is close to that of the BCR-2 (53.2\%) (Table 1), consistent with our assumption

Table 1. Comparison of Elemental Concentration of Reported Oregon Basalt (BCR-2) and the Measured Hanford Basaltic Clast ${ }^{a}$

\begin{tabular}{llrcc}
\hline & element & BCR-2 & $\begin{array}{c}\text { Hanford } \\
\text { basaltic clast }\end{array}$ & $\begin{array}{c}\text { difference } \\
\text { percentage based } \\
\text { on BCR-2 }\end{array}$ \\
$\begin{array}{c}8 \text { major } \\
\text { elements }\end{array}$ & $\mathrm{Si}$ & 25.3 & $30.5(30.4)$ & $20.5 \%(20.2 \%)$ \\
$(\%)$ & $\mathrm{Al}$ & 7.1 & $8.2(8.4)$ & $15.2 \%(17.2 \%)$ \\
& $\mathrm{Fe}$ & 9.7 & $0.5(0.4)$ & $-95.0 \%(-95.4 \%)$ \\
& $\mathrm{Mg}$ & 2.2 & $2.2(2.1)$ & $2.2 \%(-0.8 \%)$ \\
& $\mathrm{Ca}$ & 5.1 & $7.6(7.5)$ & $49.6 \%(47.9 \%)$ \\
& $\mathrm{Na}$ & 2.3 & $2.6(2.6)$ & $12.5 \%(11.0 \%)$ \\
trace & $\mathrm{K}$ & 1.5 & $0.2(0.1)$ & $-90.7 \%(-91.2 \%)$ \\
& $\mathrm{Mn}$ & 0.0 & $0.2(0.2)$ & $\mathrm{NA}$ \\
& $\mathrm{total}$ of 8 & 53.2 & $52.0(51.8)$ & $-2.1 \%(-2.5 \%)$ \\
$\mathrm{V}$ & 416.0 & $432.8(379.1)$ & $4.0 \%(-8.9 \%)$ \\
& $\mathrm{Cu}$ & 19.0 & $36.2(29.8)$ & $90.4 \%(56.8 \%)$ \\
& $\mathrm{Rb}$ & 48.0 & $64.0(58.0)$ & $33.3 \%(20.8 \%)$ \\
& $\mathrm{Sr}$ & 346.0 & $368.8(370.8)$ & $6.6 \%(7.2 \%)$ \\
& $\mathrm{Zr}$ & 188.0 & $167.1(163.4)$ & $-11.1 \%(-13.1 \%)$ \\
& $\mathrm{Ba}$ & 683.0 & $517.7(501.6)$ & $-24.2 \%(-26.6 \%)$ \\
& $\mathrm{Ce}$ & 53.0 & $35.4(34.3)$ & $-33.3 \%(-35.2 \%)$ \\
& $\mathrm{Th}$ & 6.2 & $4.5(4.4)$ & $-27.5 \%(-29.0 \%)$ \\
& $\mathrm{U}$ & 1.7 & $2.9(2.3)$ & $69.3 \%(33.5 \%)$
\end{tabular}

${ }^{a}$ For the Hanford basaltic clast values and difference percentages, values in parentheses are based on only the 3 deepest ablation layers, so as to better approximate the unweathered condition. NA: Not applicable.

of constant cumulative mass fraction of these elements. Individual element mass fractions of the Hanford basaltic clast vary more widely in comparison to BCR-2. Among the eight major elements, $\mathrm{Fe}, \mathrm{Mn}, \mathrm{Mg}$, and $\mathrm{K}$ were especially variable spatially. Fe concentration was monitored via ${ }^{54} \mathrm{Fe}$, an isotope with natural abundance of just $5.82 \%$; the higher abundance isotope ${ }^{56} \mathrm{Fe}$ was not monitored because of polyatomic interference from ${ }^{40} \mathrm{Ar}^{16} \mathrm{O}$. Likewise, polyatomic interferences of ${ }^{16} \mathrm{O}^{39} \mathrm{~K},{ }^{1} \mathrm{H}^{23} \mathrm{Na}$, and ${ }^{16} \mathrm{O}^{23} \mathrm{Na}$ could increase the background signals for the low-mass isotopes of ${ }^{55} \mathrm{Mn},{ }^{24}$ $\mathrm{Mg}$, and ${ }^{39} \mathrm{~K}$ detecting in the ICP-MS analysis.
For the trace elements, differences between the Hanford basaltic clast and BCR-2 are mostly within $\pm 30 \%$, except for $\mathrm{Rb}$ (overall average only), $\mathrm{Cu}, \mathrm{U}$, and $\mathrm{Ce}$ (Table 1 ). $\mathrm{U}$ and $\mathrm{Cu}$ are known contaminant elements at the Hanford 300 Area. The elemental fractionation difference between the reference material and sample, exhibiting different matrix composition, is another obstacle for getting quantitative concentration measurement using LA-ICP-MS analysis. ${ }^{16}$ We expect that the elemental fractionation between SRM 610 and basaltic clast sample was reduced through the use of a short-UV laser (213 $\mathrm{nm}$ ) to produce relatively small-sized aerosols, and the use of helium as the carrier gas to transport aerosols to ICP-MS detector for enhanced signal sensitivity. ${ }^{29-32}$

3.2.1. Mapping Results. Intrinsic and Possible Contaminant Elements. Figure 1 shows $3-\mathrm{D}$ maps of three elements that are intrinsic to the basaltic clast sample: Si (30.5\% of the clast), $\mathrm{Na}(2.6 \%)$, and $\mathrm{Sr}(369 \mathrm{mg} / \mathrm{kg})$. Maps for other intrinsic elements and possible contaminant elements $(\mathrm{V}$, $\mathrm{Ni}$, and $\mathrm{Zr}$; c.f. 33) are shown in Figure S3 in the Supporting Information. Distributions of $\mathrm{Si}, \mathrm{Na}$, and $\mathrm{Sr}$ with depth are basically uniform, with slightly higher concentrations of $\mathrm{Si}$ and $\mathrm{Na}$ near the surface.

To facilitate comparison of concentration profiles among different elements, we first define a relative average concentration. Each element's concentration was averaged over the 441 spots of each depth (layer). These average concentrations were then normalized by dividing by the average concentration of the three deepest layers. Consistent with the 3-D maps, $\mathrm{Si}$ and $\mathrm{Na}$ concentrations show similar increases (Figure S4) near the surface of the basaltic clast. Conversely, Ca concentration decreases slightly toward the surface, possibly because Ca-containing minerals are either leached away, or dissolved when near the grain surface. Possible contaminant elements $\mathrm{V}, \mathrm{Ni}, \mathrm{Ba}$, and $\mathrm{Th}$ have higher concentrations in the middle layers, from 1.1 to $4.5 \mu \mathrm{m}$. This may indicate some historical precipitation or adsorption onto the grain, followed by ongoing dissolution or desorption from the grain. Nevertheless, the concentration variations for these elements are small compared to the major contaminant elements $\mathrm{U}$ and $\mathrm{Cu}$.

3.2.2. Known Contaminant Elements $U, C u$, and Al. $U$ and $\mathrm{Cu}$ show accumulation at the surface layers (Figure 2). The $\mathrm{Cu}$ concentration is well distributed within each layer, while $\mathrm{U}$ in the near-surface layers is concentrated at just a few spots. This suggests the possibility of two distinct types of contaminated microsites, one having relatively high concentrations ( $>30$ ppm) but occurring in a few discrete points, the other with relatively smaller concentrations $(<30 \mathrm{ppm})$ but occurring more continuously. Below the first three near-surface layers $(2.8 \mu \mathrm{m}), \mathrm{U}$ concentration rapidly approaches the background level of $\sim 2.3 \mathrm{ppm}$, except for several spots at the right-bottom area where above-background concentrations extend to $4.5 \mu \mathrm{m}$. Mean $\mathrm{U}$ concentration $C^{\mathrm{U}}$ as a function of depth $l$ in $\mu \mathrm{m}$ (Figure 3) is well characterized by

$$
C^{\mathrm{U}}(l)=B+\left\{\begin{array}{l}
\left(\frac{b}{l}\right)^{0.81} l<\chi \\
0 \text { otherwise }
\end{array}\right.
$$

where $\chi \approx 20 \mu \mathrm{m}$ is the depth beyond which $\mathrm{U}$ concentration is constant, $B$ is the background $U$ concentration (given by the mean of layers deeper than $\chi$ as $2.3 \mathrm{mg} \mathrm{kg}^{-1}$ ), and $b \approx 13.8 \mu \mathrm{m}$ 

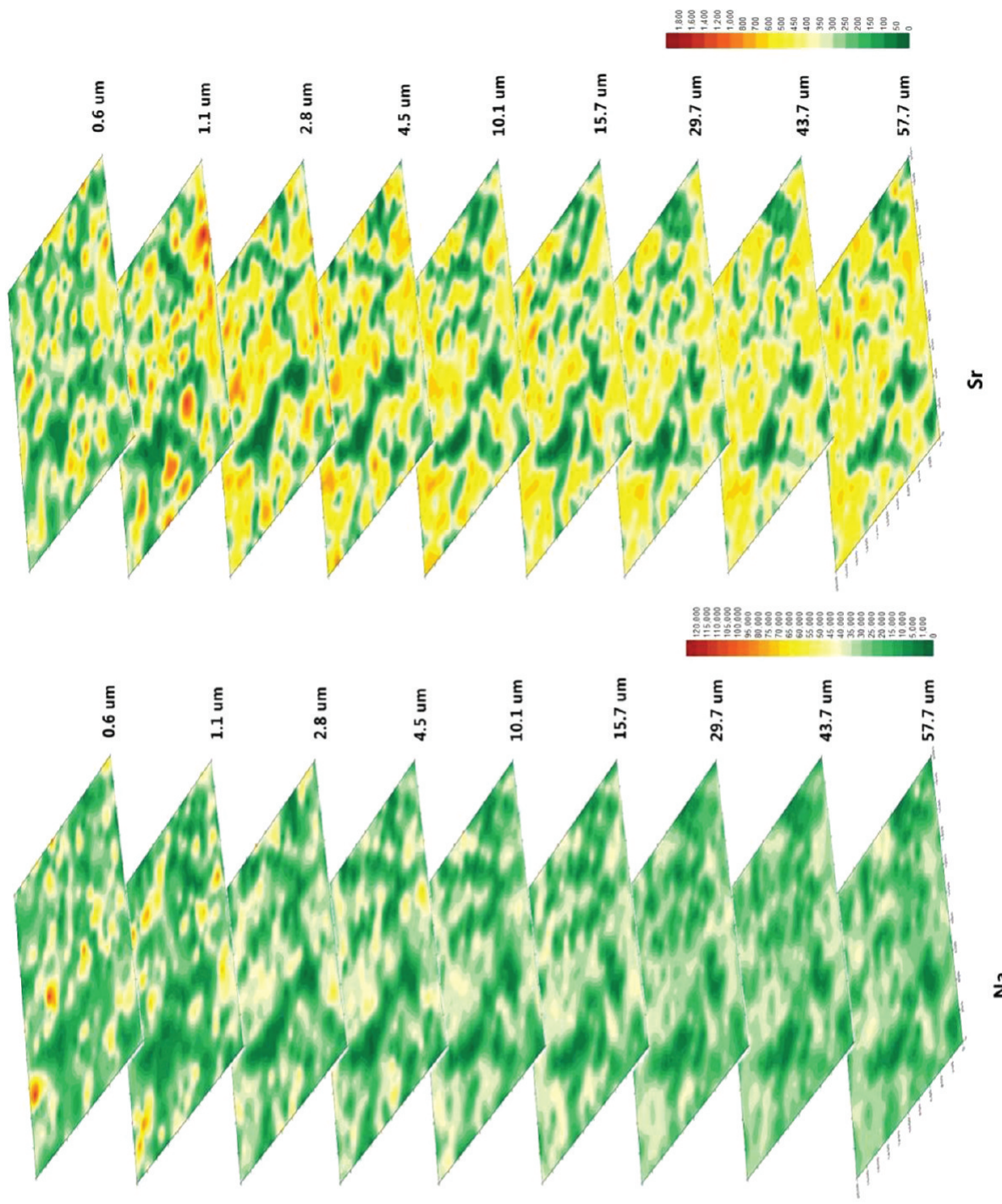



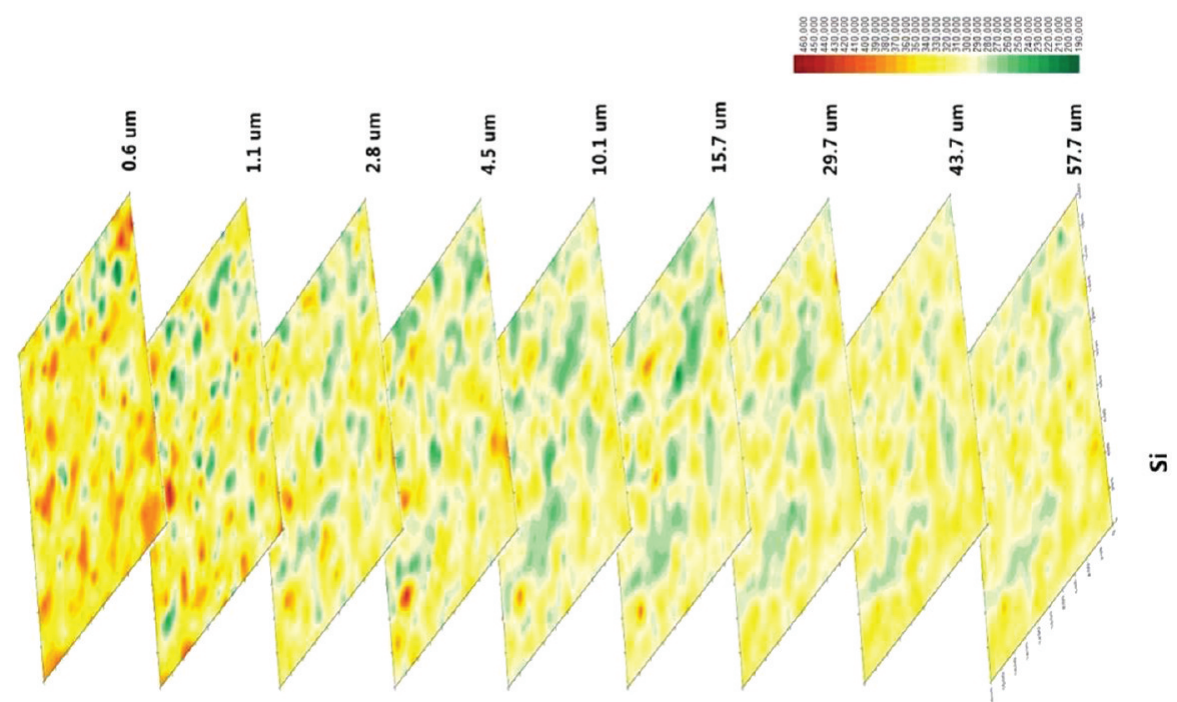

Figure 1. 3-D maps for background elements: $\mathrm{Si}, \mathrm{Na}$, and $\mathrm{Sr}$.

$\mathrm{ppm}^{1 / 0.81}$. The values of the exponent and $b$ were estimated by nonlinear least-squares.

$\mathrm{Cu}$ concentrations in the outermost layers show a consistent spatial pattern in the sampled $2.1 \mathrm{~mm} \times 2.1 \mathrm{~mm}$ area, and the patterning is apparent to deeper depths than it is for U. Nonetheless, $\mathrm{Cu}$ concentration also follows a power-law distribution (eq 10), with exponent 0.62, b $\approx 944 \mu \mathrm{m}$ $\mathrm{ppm}^{1 / 0.62}$, and background $B \approx 30 \mathrm{mg} \mathrm{kg}^{-1}$ (Figure 3 ). The 

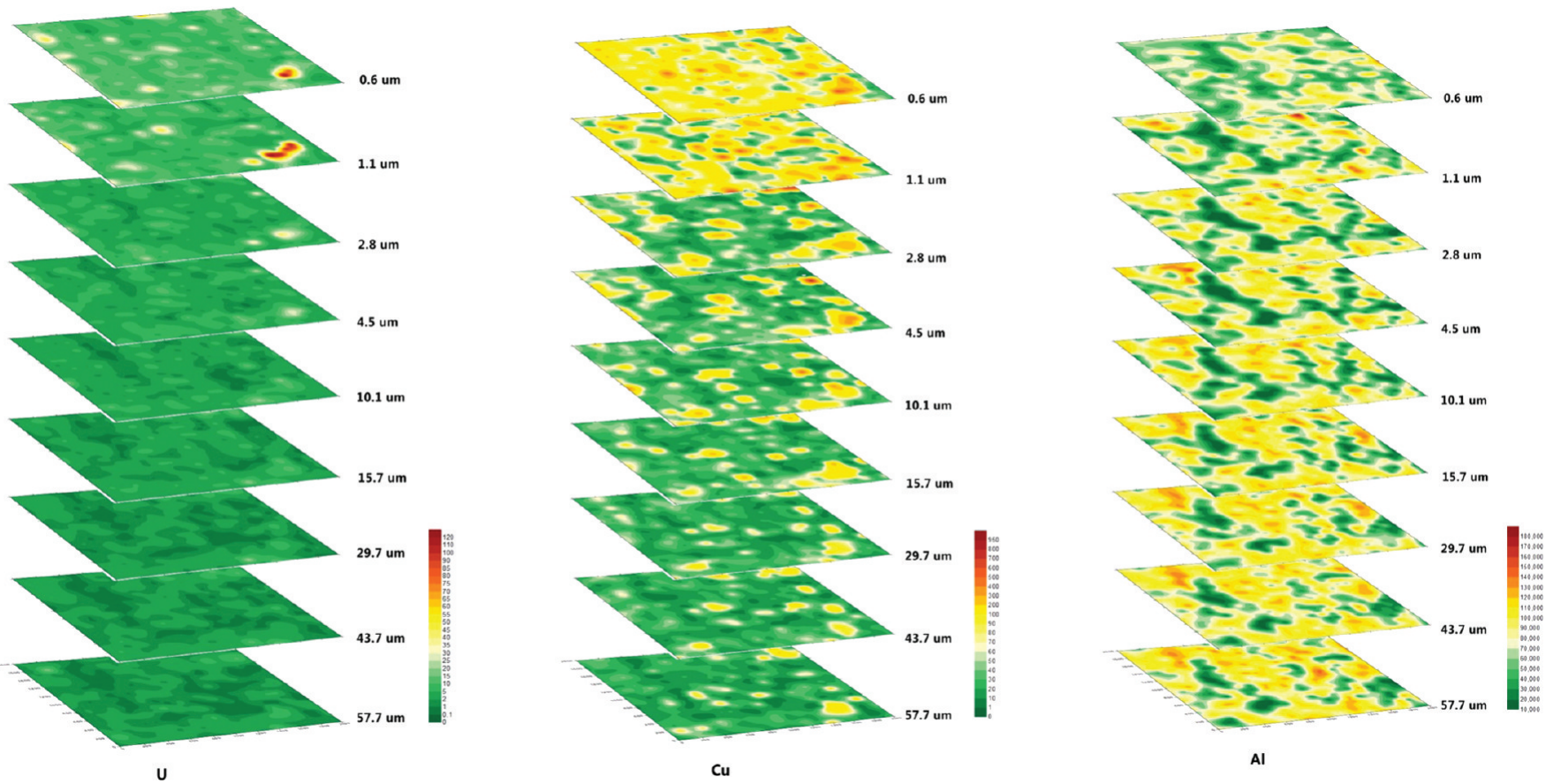

Figure 2. 3-D maps for $\mathrm{U}, \mathrm{Cu}$, and $\mathrm{Al}$.

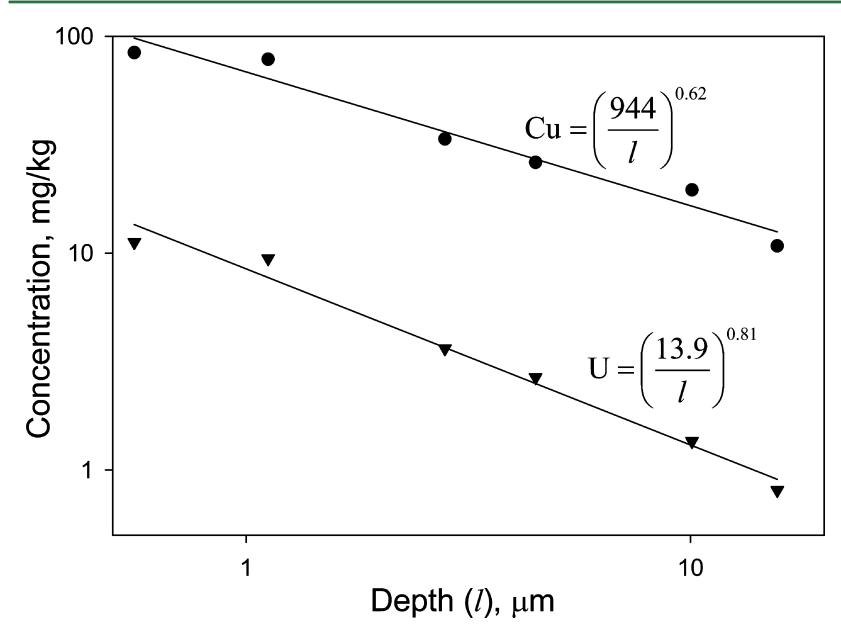

Figure 3. Measured and fitted concentrations of $\mathrm{U}$ and $\mathrm{Cu}$ with depth.

slightly steeper slope for $\mathrm{U}$ indicates a greater tendency toward precipitation or sorption for $\mathrm{U}$ than for $\mathrm{Cu}$. The high $\mathrm{Cu}$ concentration spots at the bottom layers may be caused either by preferential diffusion pathways or by high background at those spots. According to Arai et al. ${ }^{2}$ and Singer et al., ${ }^{4}$ evidence shows that $\mathrm{U}$ at high concentration spots coexists with $\mathrm{Cu}$ as metatorbernite $\left(\mathrm{Cu}\left(\mathrm{UO}_{2} \mathrm{PO}\right) \cdot 8 \mathrm{H}_{2} \mathrm{O}\right)$ in the upper vadose zone of the Hanford 300-Area. Our basaltic clast sample was collected from the smear zone, and the $\mathrm{U}$ and $\mathrm{Cu}$ maps show that while high $\mathrm{U}$ concentration spots correspond to high $\mathrm{Cu}$ concentration, there are also high $\mathrm{Cu}$ spots without high $\mathrm{U}$. This implies that $U$ in the smear zone may also exist as other forms such as an adsorbed phase, as seen in the lower vadose zone. ${ }^{11}$ In addition to $\mathrm{U}$ and $\mathrm{Cu}$, we also see accumulation of $\mathrm{Rb}$ at the grain surface (Figure S3 in the Supporting Information), consistent with the $33.3 \%$ overabundance of $\mathrm{Rb}$ in Hanford basaltic clast compared to that in BCR-2.

Aluminum was reported to be present in the 300 Area contaminant in the form of a dissolved aluminum cladding

(basic sodium aluminate) within the copper-uranium-nitric acid solutions. ${ }^{2}$ However, no accumulation of $\mathrm{Al}$ at the outer layers is observed (Figure S3 in Supporting Information); in fact, $\mathrm{Al}$ actually has a lower relative concentration near the surface (Figure S4), suggesting that rather than the basaltic clast being a repository phase for contaminant $\mathrm{Al}$, some intrinsic $\mathrm{Al}$ was leached out.

3.2.3. Interpretation of Spatial Patterns of Element Distribution. The extreme chemistry (extreme $\mathrm{pH}$ values, very high salts, etc.) of the released waste, and the oscillating groundwater table, complicate the interpretation of 3-D element distributions within our basaltic clast sample. During the 32-year contaminant release period (1943-1975), water mounded beneath the ponds, dispersing the waste during emplacement. The $\mathrm{pH}$ of the pond water ranged from 1.8 to 11.4: when the water was acidic, sodium hydroxide was added to the waste stream in an attempt to minimize mobilization of $\mathrm{Cu}$ and $\mathrm{U}$ in the vadose zone. ${ }^{33}$ Furthermore, the site is bounded to the east by the Columbia River, the stage of which oscillates both daily and seasonally (e.g., 23). The resulting dynamic flow conditions could yield a complex scenario of dissolution, sorption, and back-and-forth intragranular diffusion of various elements within the basaltic grain.

The 3-D mapping is strongly anisotropic, having a depth resolution in the range of $0.5-15 \mu \mathrm{m}$, while spatial resolution in the other two dimensions is fixed at $100 \mu \mathrm{m}$ by the laser spot diameter. This anisotropy is evident in how closely different layers of the 3-D element maps resemble each other, and highlights the extremely rapid decreases in $\mathrm{U}$ and $\mathrm{Cu}$ concentrations with depth. Intragranular pores in the Hanford basaltic clast are expected to have widths in the range of nanometers to micrometers, so we may infer that the high $U$ and $\mathrm{Cu}$ concentrations indicate intragranular pores where $\mathrm{U}$ and $\mathrm{Cu}$ have been adsorbed. Spatial covariance of the various elements (Table S3) shows that $U$ concentration is strongly correlated with those of $\mathrm{Cu}$ (a known contaminant), Th (a possible contaminant), and intrinsic elements $\mathrm{Mn}$ and Ce. Most 
Table 2. Particle Size Distribution and Calculated U Fraction of Two Hanford 300 Area Sediments ${ }^{a}$

\begin{tabular}{|c|c|c|c|c|c|c|c|c|}
\hline \multirow[b]{2}{*}{ distribution source } & \multicolumn{6}{|c|}{ particle size mass fraction } & \multicolumn{2}{|c|}{$\begin{array}{l}\mathrm{U} \text { in coarse fraction with } \\
\text { background } \mathrm{U} \text { of }\end{array}$} \\
\hline & $d>32$ & $32>d>16$ & $16>d>8$ & $8>d>4$ & $4>d>2$ & $2>d$ & $0.0 \mathrm{ppm}$ & $2.3 \mathrm{ppm}$ \\
\hline mean of core IFRC-C6210 & 3.2 & 15 & 14 & 10.4 & 8.2 & 49.2 & 1.4 & 30.9 \\
\hline smear zone composite & 7 & 20.3 & 17.9 & 11.6 & 10 & 33.3 & 1.2 & 29.4 \\
\hline
\end{tabular}

of the higher covariances (Table S3) are due to elemental composition of common minerals. For example, $\mathrm{Ca}$ is correlated with $\mathrm{Mg}$ because they co-occur in carbonates and some rock-forming minerals in basalts, and is negatively correlated with $\mathrm{Na}, \mathrm{Al}, \mathrm{Si}$, and $\mathrm{K}$. Likewise, $\mathrm{Fe}, \mathrm{V}$, and $\mathrm{Ni}$ substitute for each other in some minerals because of their similar ionic radius, giving rise to their strong co-occurrence. The correlation between $\mathrm{Al}$ and $\mathrm{Na}$ may be ordinary mineralogy, or it may indicate $\mathrm{Al}$ precipitation following injection of $\mathrm{NaOH}$ at the 300 Area.

3.2.4. Estimation of $U$ Mass Fraction in Gravel and Cobbles. Most work on the Hanford 300 Area has focused on the $<2 \mathrm{~mm}$ fraction, because most of the sorbed $\mathrm{U}(\mathrm{VI})$ is associated with carbonate and phosphate minerals, clays, and micas. ${ }^{23}$ However, the Hanford sediments are predominantly gravel and cobbles. $U$ in this coarse fraction $(>2 \mathrm{~mm})$ is usually expressed as a mean concentration for the bulk grains, but because mean $U$ concentration of a crushed cobble is generally below detection limits, ${ }^{1}$ it is hard to reliably estimate the percentage of contaminant $U$ that is associated with the coarse fraction. For example, according to the particle size distribution and $U$ concentration measurement in Liu et al., gravel and cobbles may contain from $0 \%$ to $83.2 \%$ of the total U. Our measurements of the outer $58-\mu \mathrm{m}$ skin of a coarse basaltic grain, combined with the $0.1 \mathrm{mg} / \mathrm{kg}$ detection limit achieved by LA-ICP-MS, enable us to reduce that uncertainty.

The particle size distribution at the 300 Area is quite variable: "a remarkable feature of the sediments is the variation in grain size distributions over a small lateral or vertical scale". ${ }^{34}$ For this analysis we used two particle size distributions: core IFRCC6210, sampled at approximately 64-cm intervals to a depth of $19 \mathrm{~m}$, and a composite sample of the 300 Area smear zone. Properties are shown in Table 2. For a given particle radius $R$, we calculate the mass $M$ of contaminant $\mathrm{U}$ as

$$
M=\frac{4 \pi \rho B}{3} R^{3}+4 \pi \rho \int_{R-\chi}^{R}\left[\frac{b}{R-r}\right]^{0.81} r^{2} d r
$$

where $\rho$, the bulk density of basalt, is assumed to be $2.65 \mathrm{~kg}$ $\mathrm{L}^{-1}$. Dividing the mass of contaminant $\mathrm{U}$ by the mass of the whole particle then gives a mean concentration for that particle size. Within each particle size class, we used the geometric mean radius. The mean concentration for the fraction of (sand + fines), reported by Liu et al. ${ }^{5}$ as $47.8 \mathrm{nmol} / \mathrm{g}(=11.4 \mathrm{mg} / \mathrm{kg})$, was used for all particles $<2 \mathrm{~mm}$.

When the background $U$ is set to $B=0.0$ in eq 11 , the coarse fraction contains just over $1 \%$ of the total $U$ (Table S4). But when background $U$ is set to our measured value of $2.3 \mathrm{ppm}$, the coarse fraction contains approximately $30 \%$ of the contaminant $\mathrm{U}$. That is, almost all of the $\mathrm{U}$ in the coarse fraction is naturally occurring. Nonetheless, $U$ concentrations near the surface of the rocks in the coarse fraction are well above the background level. Further testing is required to better assess how representative these results are of the 300 Area as a whole, and thus to evaluate the importance of the coarse fraction as a long-term source of contaminant $U$.

\section{ASSOCIATED CONTENT}

\section{Supporting Information}

Description of LA-ICP-MS instrument and operational conditions, Figures S1-S4, and Tables S1-S3. This material is available free of charge via the Internet at http://pubs.acs.org.

\section{AUTHOR INFORMATION}

\section{Corresponding Author}

*Phone: (817) 272-5398; e-mail: maxhu@uta.edu.

\section{ACKNOWLEDGMENTS}

This work was partially funded by Subsurface Science Scientific Focus Area, Pacific Northwest National Laboratory, Richland, WA. PNNL is operated for DOE by Battelle under contract DE-AC06-76RLO 1830. This research was also supported by the Subsurface Biogeochemical Research program DESC0005394, Office of Biological and Environmental Research, U.S. Department of Energy, for projects ER65073 and ER65074. We thank Jiangkun Du for the help in LA-ICP-MS data collection, and Christina Munoz for assistance in classifying the $>2 \mathrm{~mm}$ size fraction.

\section{REFERENCES}

(1) Zachara, J.; Brown, C.; Christensen, J.; Davis, J. A.; Dresel, E.; Liu, C.; Kelly, S.; McKinley, J.; Serne, J.; Um, W. A Site-Wide Perspective on Uranium Geochemistry at the Hanford Site; PNNL17031;Pacific Northwest National Laboratory: Richland, WA, 2007; $224 \mathrm{pp}$.

(2) Arai, Y.; Marcus, M. A.; Tamura, N.; Davis, J. A.; Zachara, J. M. Spectroscopic evidence for uranium bearing precipitates in vadose zone sediments at the Hanford 300-Area site. Environ. Sci. Technol. 2007, 41, 4633-4639.

(3) Gerber, M. S. Past Practices Technical Characterization Study: 300 Area, Hanford Site; WHC-MR-0388; Westinghouse Hanford Company: Richland, WA, 1992.

(4) Singer, D. M.; Zachara, J. M.; Brown, G. E. Uranium speciation as a function of depth in contaminated Hanford sediments - A micro$\mathrm{XRF}$, micro-XRD, and micro- and bulk-XAFS study. Environ. Sci. Technol. 2009, 43, 630-636.

(5) Liu, C.; Zachara, J. M.; Qafoku, N.; Wang, Z. Scale-dependent desorption of uranium from contaminated subsurface sediments. Water Resour. Res. 2008, 44, W08413 DOI: 10.1029/2007WR006478.

(6) Catalano, J. G.; Heald, S. M.; Zachara, J. M.; Brown, G. E. Spectroscopic and diffraction study of uranium speciation in contaminated vadose zone sediments from the Hanford site, Washington State. Environ. Sci. Technol. 2004, 38, 2822-2828.

(7) Wang, Z. M.; Zachara, J. M.; McKinley, J. P.; Smith, S. C. Cryogenic laser induced $\mathrm{U}(\mathrm{VI})$ fluorescence studies of a $\mathrm{U}(\mathrm{VI})$ substituted natural calcite: Implications to $\mathrm{U}(\mathrm{VI})$ speciation in contaminated Hanford sediments. Environ. Sci. Technol. 2005, 39, $2651-2659$

(8) Catalano, J. G.; McKinley, J. P.; Zachara, J. M.; Heald, S. M.; Smith, S. C.; Brown, G. E. Changes in uranium speciation through a 
depth sequence of contaminated Hanford sediments. Environ. Sci. Technol. 2006, 40, 2517-2524.

(9) Brown, C. F.; Jeffrey, S. R.; Catalano, J. G.; Krupka, K. M.; Icenhower, J. P. Mineralization of contaminant uranium and leach rates in sediments from Hanford, Washington. Appl. Geochem. 2009, No. 10.1016/j.apgeochem.2009.10.005.

(10) Ilton, E. S.; Qafoku, N. P.; Liu, C. X.; Moore, D. A.; Zachara, J. M. Advective removal of intraparticle uranium from contaminated vadose zone sediments, Hanford, US. Environ. Sci. Technol. 2008, 42, $1565-1571$.

(11) Liu, C.; Shi, Z.; Zachara, J. M. Kinetics of uranium (VI) desorption from contaminated sediments: Effect of geochemical conditions and model evaluation. Environ. Sci. Technol. 2009, 43, 6560-6566.

(12) Qafoku, N. P.; Zachara, J. M.; Liu, C.; Gassman, P. L.; Qafoku, O. S.; Smith, S. C. Kinetic desorption and sorption of U(VI) during reactive transport in a contaminated Hanford sediment. Environ. Sci. Technol. 2005, 39, 3157-3165.

(13) Longerich, H. P. Laser ablation-inductively coupled plasma-mass spectrometry: An introduction. In Laser-Ablation-ICP-MS in the Earth Sciences: Current Practices and Outstanding Issues; Sylvester, P., Ed.; Mineralogical Association of Canada, 2008; Vol. 40, pp 1-18.

(14) Russo, R. E.; Mao, X. L.; Liu, H. C.; Gonzalez, J.; Mao, S. S. Laser ablation in analytical chemistry - A review. Talanta 2002, 57, 425-451.

(15) Sylvester, P. J. LA-(MC)-ICP-MS trends in 2006 and 2007 with particular emphasis on measurement uncertainties. Geostand. Geoanal. Res. 2008, 32 (4), 469-488.

(16) Jackson, S. E. Calibration strategies for elemental analysis by LAICP-MS. In Laser-Ablation-ICP-MS in the Earth Sciences: Current Practices and Outstanding Issues; Sylvester, P., Ed.; Mineralogical Association of Canada, 2008; Vol. 40, pp 169-188.

(17) Longerich, H. P.; Jackson, S. E.; Günther, D. Laser ablation inductively coupled plasma mass spectrometric transient signal data acquisition and analyte concentration calculation. J. Anal. Atom. Spectrom. 1996, 11, 899-904.

(18) Gratuze, B. Obsidian characterization by LA-ICP-MS and its application to prehistoric trade in the Mediterranean and the Near East: Sources and distribution of obsidian within the Aegean and Anatolia. J. Archaeol. Sci. 1999, 26, 869-881.

(19) Guillong, M.; Hametner, K.; Reusser, E.; Wilson, S. A.; Günther, D. Preliminary characterization of new Glass Reference Materials (GSA-1G, GSC-1G, GSD-1G and GSE-1G) by Laser AblationInductively Coupled Plasma-Mass Spectrometry using 193 nm, 213 $\mathrm{nm}$, and $266 \mathrm{~nm}$ wavelengths. Geostand. Geoanal. Res. 2005, 29, 315331.

(20) Halicz, L.; Günther, D. Quantitative analysis of silicates using LA-ICP-MS with liquid calibration. J. Anal. Atom. Spectrom. 2004, 19, $1539-1545$.

(21) Gagnon, J. E.; Fryer, B. J.; Samson, I. M.; Williams-Jones, A. E. Quantitative analysis of silicate certified reference materials by LAICP-MS with and without an internal standard. J. Anal. Atom. Spectrom. 2008, 23, 1529-1537.

(22) Liu, Y.; Hu, Z.; Gao, S.; Günther, D.; Xu, J.; Gao, C.; Chen, H. In situ analysis of major and trace elements of anhydrous minerals by LA-ICP-MS without applying an internal standard. Chem. Geol. 2008, $257,34-43$.

(23) Yin, J.; Haggerty, R; Stoliker, D. L.; Kent, D. B.; Istok, J. D.; Greskowiak, J.; Zachara, J. M. Transient groundwater chemistry near a river: Effects on $\mathrm{U}(\mathrm{VI})$ transport in laboratory column experiments. Water Resour. Res. 2011, 47, W04502 DOI: 10.1029/2010WR009369.

(24) Horn, I.; Rudnick, R. L.; McDonough, W. F. Precise elemental and isotope ratio determination by simultaneous solution nebulization and laser ablation-ICP-MS: Application to U-Pb geochronology. Chem. Geol. 2000, 164, 281-301.

(25) Horn, I.; Gunther, D. The influence of ablation carrier gasses Ar, $\mathrm{He}$ and $\mathrm{Ne}$ on the particle size distribution and transport efficiencies of laser ablation-induced aerosols: Implications for LA-ICP-MS. Appl. Surf. Sci. 2003, 207 (1-4), 144-157.
(26) Günther, D.; Heinrich, C. A. Enhanced sensitivity in laser ablation-ICP mass spectrometry using helium-argon mixtures as aerosol carrier - plenary lecture. J. Anal. At. Spectrom. 1999, 14 (9), $1363-1368$.

(27) Koenig, A. E.; Rogers, R. E.; Trueman, C. N. Visualizing fossilization using laser ablation-inductively coupled plasma-mass spectrometry maps of trace elements in Late Cretaceous bones. Geology 2009, 37 (6), 511-514.

(28) Borisov, O. V.; Mao, X. L.; Russo, R. E. Effects of crater development on fractionation and signal intensity during laser ablation inductively coupled plasma mass spectrometry. Spectrochim. Acta, Part B 2000, 55, 1693-1704.

(29) Eggins, S. M.; Kinsley, L. P. J; Shelley, J. M. G. Deposition and element fractionation processes during atmospheric pressure laser sampling for analysis by ICP-MS. Appl. Surf. Sci. 1998, 127-129, 278286.

(30) Horn, I.; Gunther, D. The influence of ablation carrier gasses Ar, $\mathrm{He}$ and $\mathrm{Ne}$ on the particle size distribution and transport efficiencies of laser ablation-induced aerosols: Implications for LA-ICP-MS. Appl. Surf. Sci. 2003, 207 (1-4), 144-157.

(31) Günther, D.; Koch, J. Formation of aerosols generated by laser ablation and their impact on elemental fractionation in LA-ICP-MS. In Laser-Ablation-ICP-MS in the Earth Sciences: Current Practices and Outstanding Issues; Sylvester, P.; Ed.; Mineralogical Association of Canada, 2008; Vol. 40, pp 19-34.

(32) Sylvester, P. J. Matrix effect in laser ablation-ICP-MS. In LaserAblation-ICP-MS in the Earth Sciences: Current Practices and Outstanding Issues; Sylvester, P.; Ed.; Mineralogical Association of Canada, 2008; Vol. 40, pp 67-78.

(33) Hammond, G. E.; Lichtner, P. C. Field-scale model for the natural attenuation of uranium at the Hanford 300 Area using highperformance computing. Water Resour. Res. 2010, 46, W09527, 31; doi:10.1029/2009WR008819.

(34) Serne, R. J.; Brown, C. F.; Schaef, H. T.; Pierce, E. M.; Lindberg, J.; Wang, Z.; Gassmann, P.; Catalano, J. 300 Area Uranium Leach and Adsorption Project; Report PNNL-14022; 2002. 